\title{
Matlab Based Analysis of 3-Ø Self-Excited Induction Generator with Nonlinear Load
}

\author{
Shani Khandelwa1, Alka Agarwal2, Vinesh Agarwal3 \\ M.Tech. student in Electrical Engineering Department, ITM Bhilwara ${ }^{1}$, \\ Assistant Professor in Electrical Engineering Department, ITM Bhilwara ${ }^{2}$, \\ Assistant Prof essor in Electrical Engineering Department, ITM Bhilwara ${ }^{3}$
}

\begin{abstract}
In this paper MATLAB based steady-state analysis of self excited induction generator is presented and different test models are given to calculate the all parameters which are required in 3- $\phi$ cage induction motor working as a generator in the self-excited mode of operation. It is well known that, harmonics are generated at the input side of the induction generator due to the presence of nonlinear circuits (rectifier circuit). In this paper, the various nonlinear loads (rectifier loads) connected with the SEIG are simulated and evaluated. The fast Fourier transform (FFT) algorithm is used to analyze the harmonic voltages and currents under steady-state conditions. Simulation is carried out for the proposed system using MATLAB/Simulink software power system tools.

Index Terms- SEIG, Total harmonics distortion, Harmonics Factor, FFT.
\end{abstract}

\section{Introduction}

The behavior of a self-excited induction generator (SEIG) with capacitor bank has been studied for over 60 years we have studied the performance of a SEIG feeding various static loads, dynamic loads has also investigated. But now we are studying about the performance of nonlinear loads fed by a SEIG. The increasing concern to the environment and fast depleting conventional resources have motivated the researchers towards rationalizing the use of conventional energy resources and exploring.

The non-conventional energy resources to meet the ever-increasing energy demand .Induction generators are often used in wind turbines and some micro hydro installations due to their ability to produce useful power at varying speeds [1]. Induction generators require an external supply to produce a rotating magnetic flux. The external reactive supply can be supplied from the electrical grid or from the externally connected capacitor bank, once it starts producing power

\section{Induction Generator}

Similar to an induction motor. Induction generators produce electrical power when their shaft is rotated faster than the synchronous speed of the equivalent induction motor. Induction generators are often used in wind turbines and some micro hydro installations due to their ability to produce useful power at varying speeds.

To excite the generator, external reactive supply can be supplied from the electrical grid or from the externally connected capacitor bank, once it starts producing power. The rotating magnetic flux from the stator induces currents in the rotor, which also produces a magnetic field. If the rotor rotates slower than the rate of the rotating flux, the machine acts like an induction motor. If the rotor rotates faster, it acts like a generator, producing power at the synchronous frequency [2].

\section{A. Classification of Induction Generators}

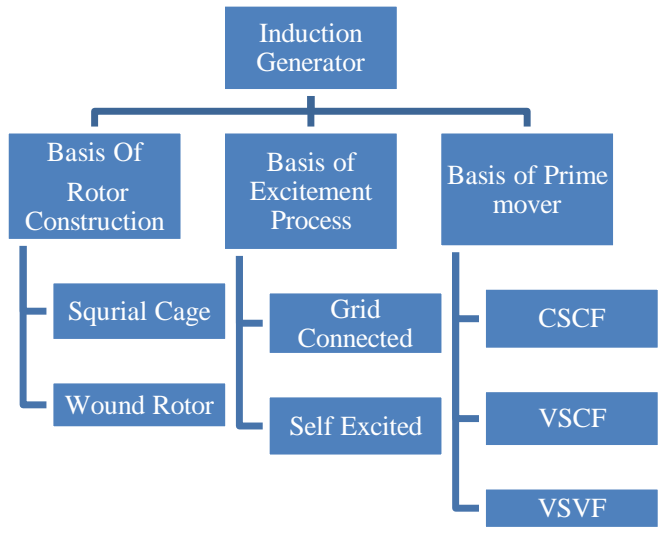

Fig:-1.1 Types of Induction Generator 


\section{Grid Connected Induction Generator}

The grid-connected induction generator (GCIG) takes the reactive power from the grid, and generates real power via slip control when driven above the synchronous speed, so it is called grid connected induction generator.

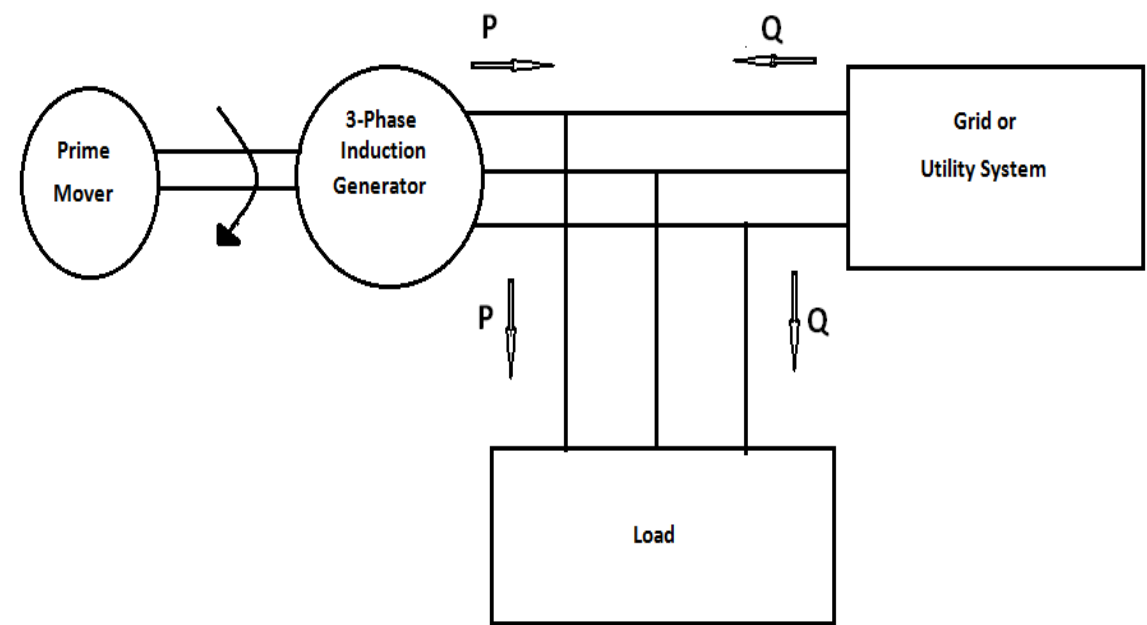

Fig:-1.2 Grid Connected Induction Generator

$>$ Self-Excited Induction Generator (SEIG)

The self excited induction generator takes the power for excitation process from a capacitor bank, connected across the stator terminals of the induction generator. This capacitor bank also supplies the reactive power to the load. [3]

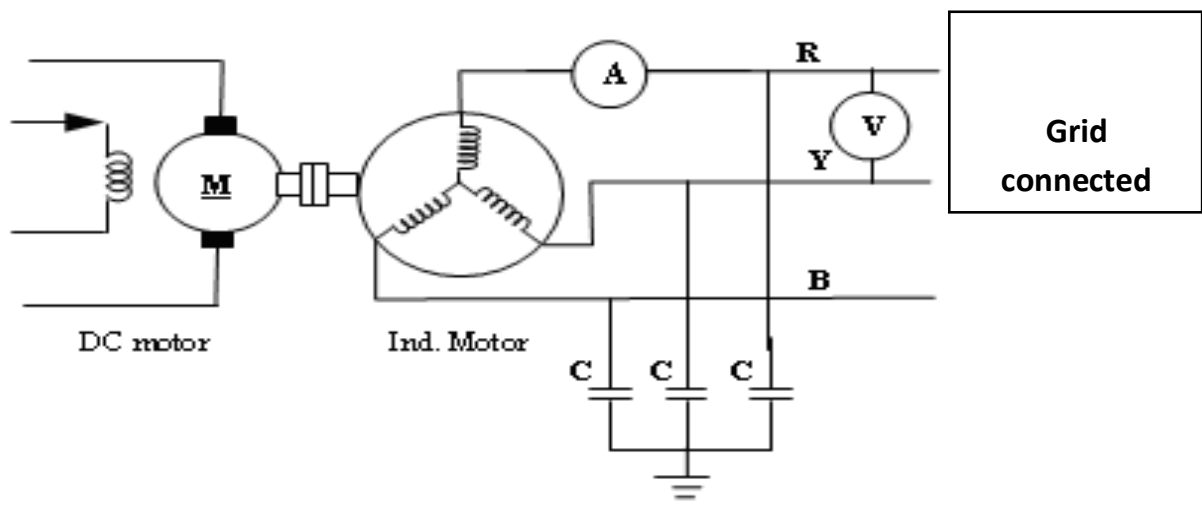

Fig: - 1.3 Self-Excited Induction Generator (SEIG)

\section{B. Merits and Demerits of Induction Generator}

\section{$>$ Merits}

- Simple and robust construction

- Run independently

- Inexpensive as compared to the conventional synchronous generator.

- Minimal maintenance

- Inherent overload protection

- Stand-alone applications, no fixed frequency

- Less material costs because of the use of electromagnets rather than Permanent magnets.

\section{$>$ Demerits}

- Requires significant reactive energy

- Poor power factor.

- Poor voltage and frequency regulation.

\section{Applications of Induction Generator}

- Electrification of far flung areas:

- For feeding critical locations:

- As a portable source of power supply 


\section{Steady State Analysis Of Seig}

Steady-state analysis of SEIG is of interest, both from the design and operational point of view. The terminal voltage and frequency are unknown and Have to be computed for a given speed, capacitance and load impedance. The analysis is complicated owing to the magnetic saturation in the machine and the need to choose suitable parameters corresponding to this saturated condition.

For the Steady-state analysis, the following assumptions are made:

(a) Only the magnetizing reactance is assumed to be affected by magnetic saturation, and all other parameters of the equivalent circuit are assumed to be constant.

(b) Leakage reactance of stator and rotor, in per unit, are taken to be equal. This assumption is normally valid in induction-machine analysis.

(c) Core loss in the machine is neglected, although the analysis can be easily extended to account for core loss.

\section{Steady State Model Of Induction Machine}

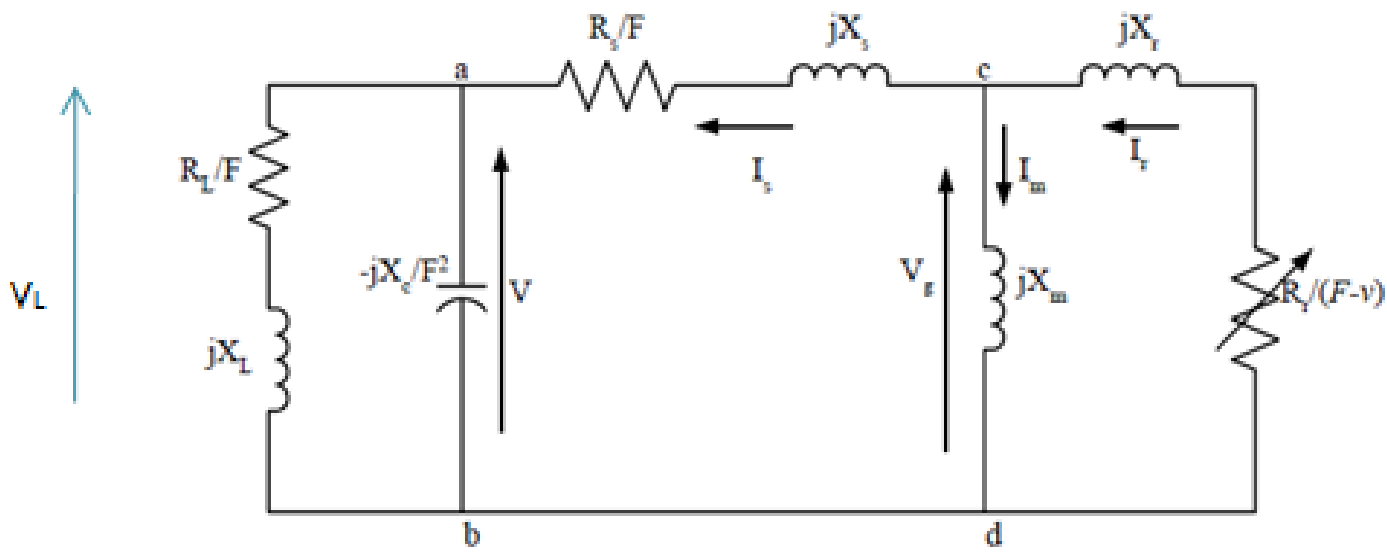

Fig: - 1.4 per phase equivalent circuit

Following two solution techniques based on the steady-state equivalent circuit are:

$>$ Nodal Admittance Method

$>$ Loop Impedance Method

\section{Determination Of Equivelent Circuit Parameters}

$>$ No Load Test

$>$ Blocked Rotor Test

$>$ D. C Test

\section{No-Load Test}

The no-load test on a Squirrel cage induction motor is conducted to measure the rotational losses of the motor and to determine some of its equivalent circuit parameters. In this test, a rated, balanced ac voltage at a rated frequency is applied to the stator while it is running at no load, and input power, voltage, and phase currents are measured at the no-load condition. 


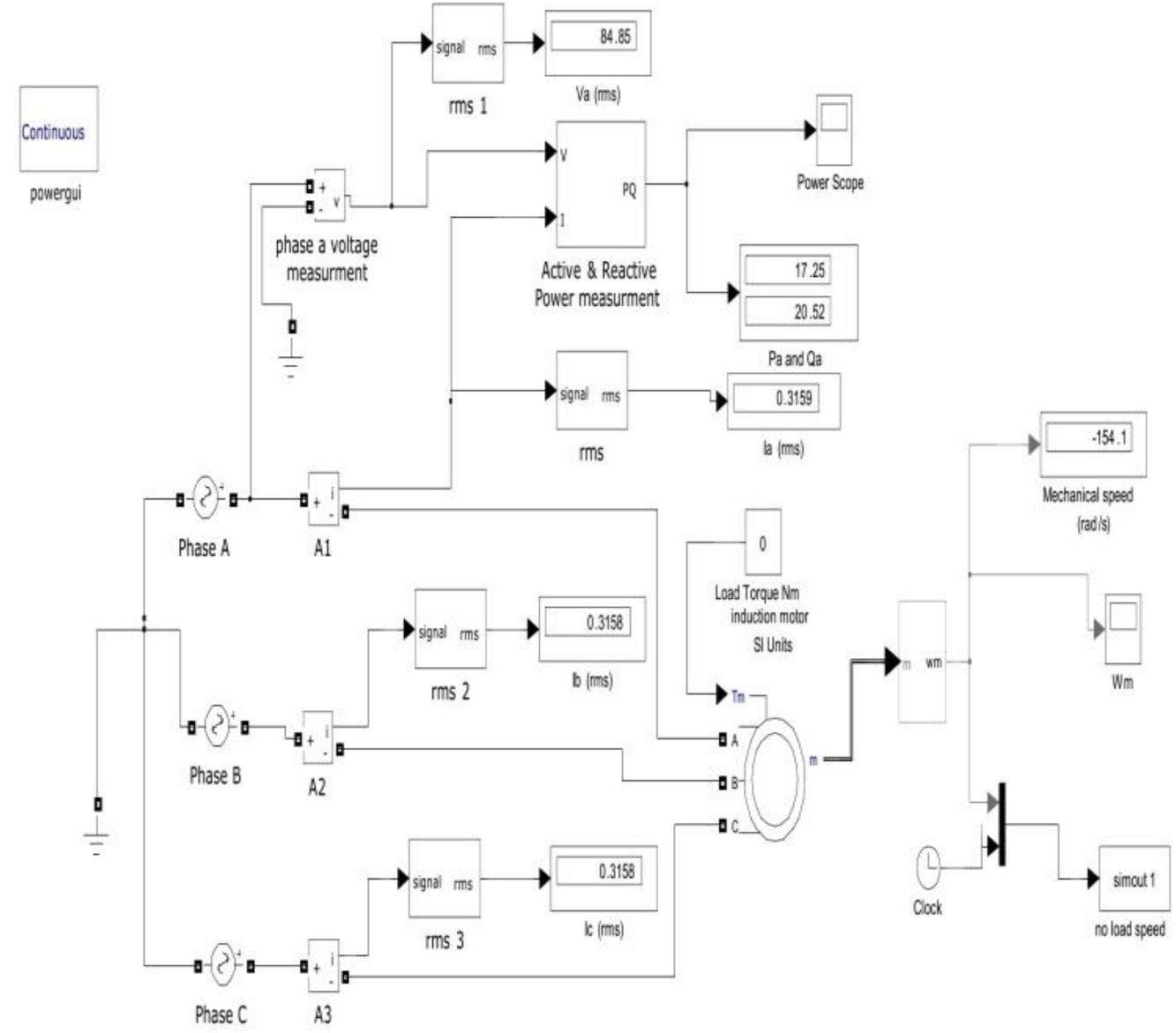

\section{Blocked Rotor Test}

Fig: -1.5 simulink diagram of no load test

The blocked-rotor test on an induction motor is performed to determine some of its equivalent circuit parameters. In this test, the rotor of the induction motor is blocked, and a reduced voltage is applied to the stator terminals so that the rated current flows through the stator windings. The input power, voltage, and current are measured 


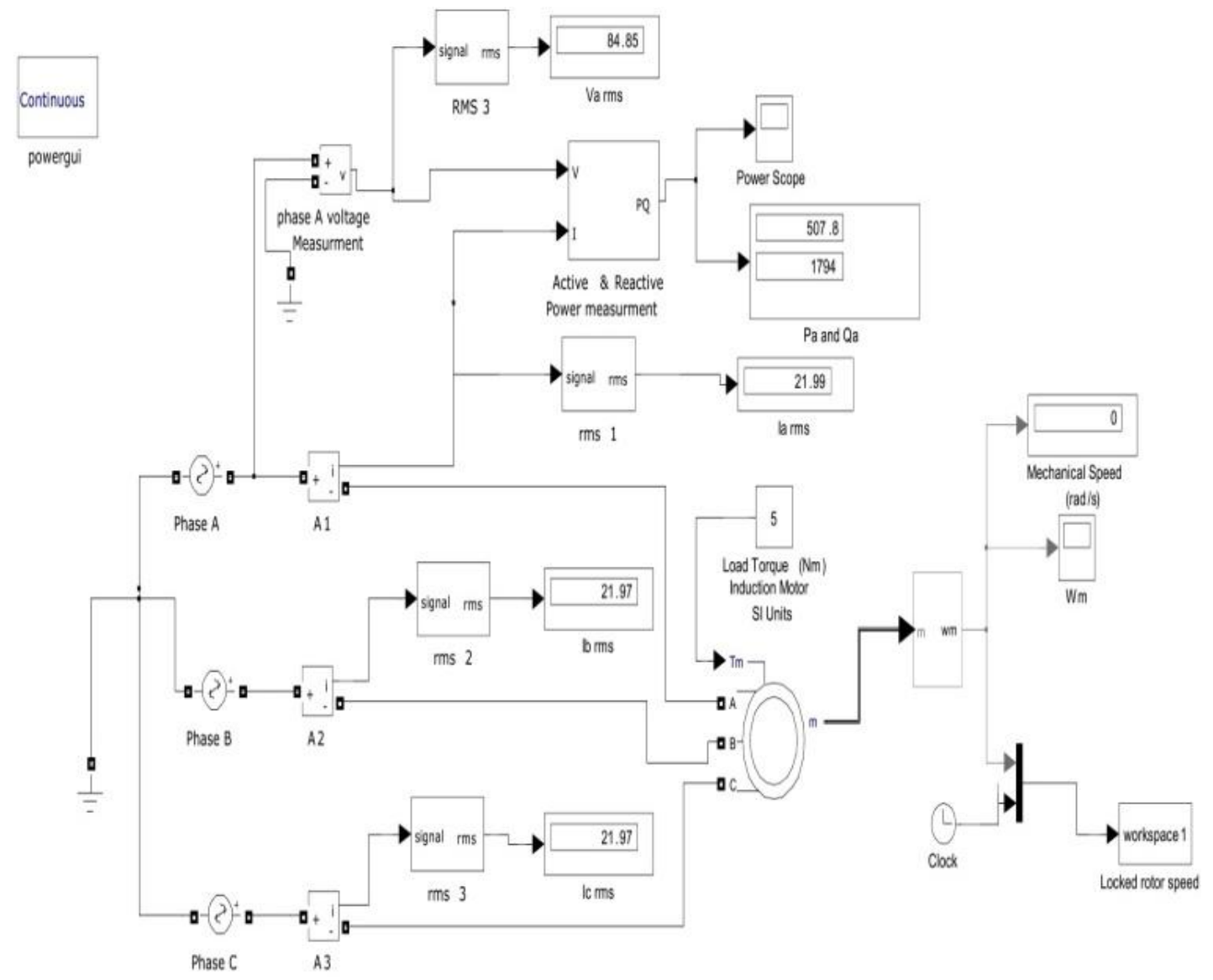

Fig: -1.6 simulink diagram of block rotor test

\section{Measurement of Stator Resistance (D.C Test)}

The dc test is performed to compute the stator winding resistance $R_{1}$. A dc voltage is applied to the stator windings of an induction motor. The resulting current flowing through the stator windings is a dc current; thus, no voltage is induced in the rotor circuit, and the motor reactance is zero. The stator resistance is the only circuit parameter limiting current flow. [4]

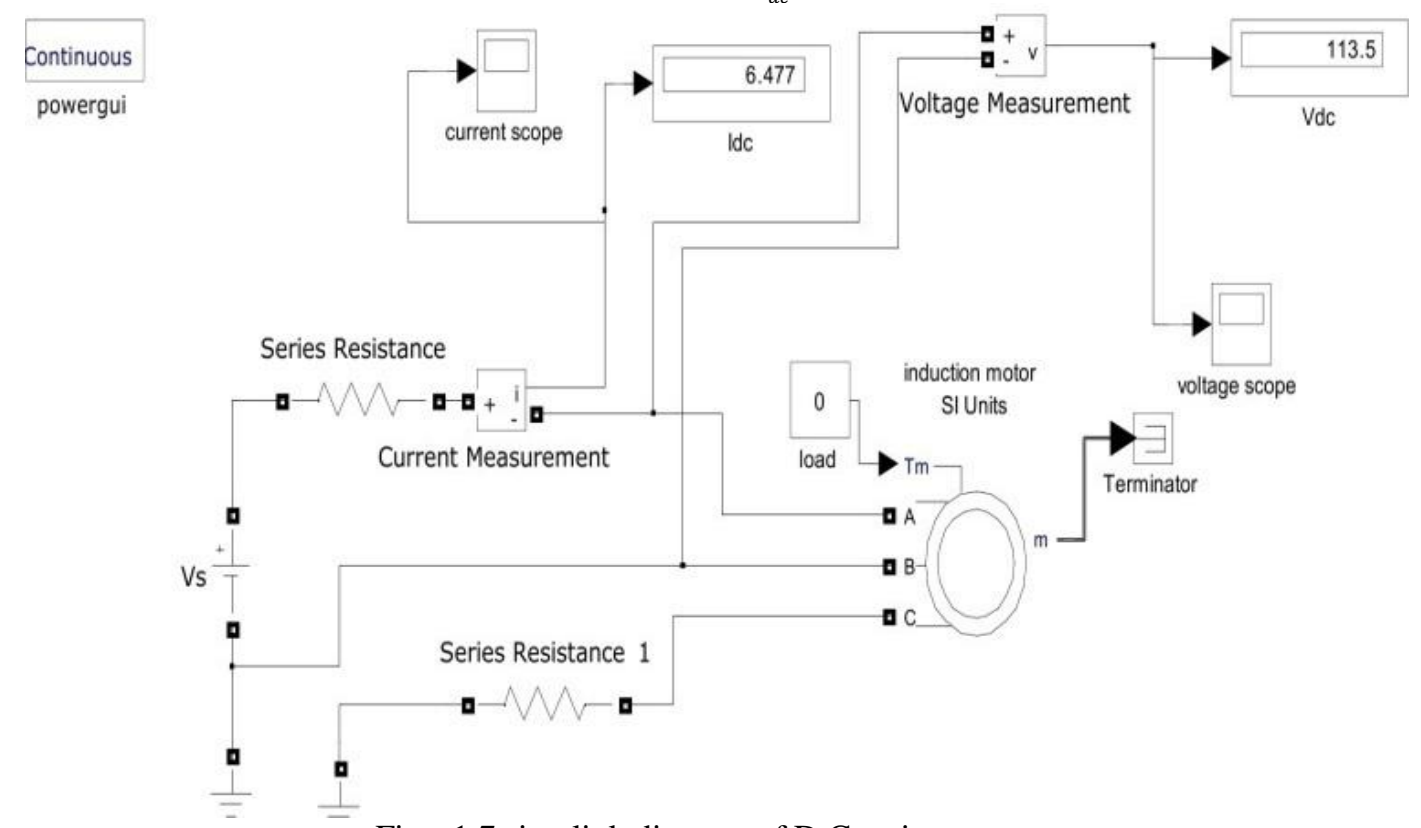

Fig: -1.7 simulink diagram of D.C resistance test 


\section{Matlab/Simulink Models}

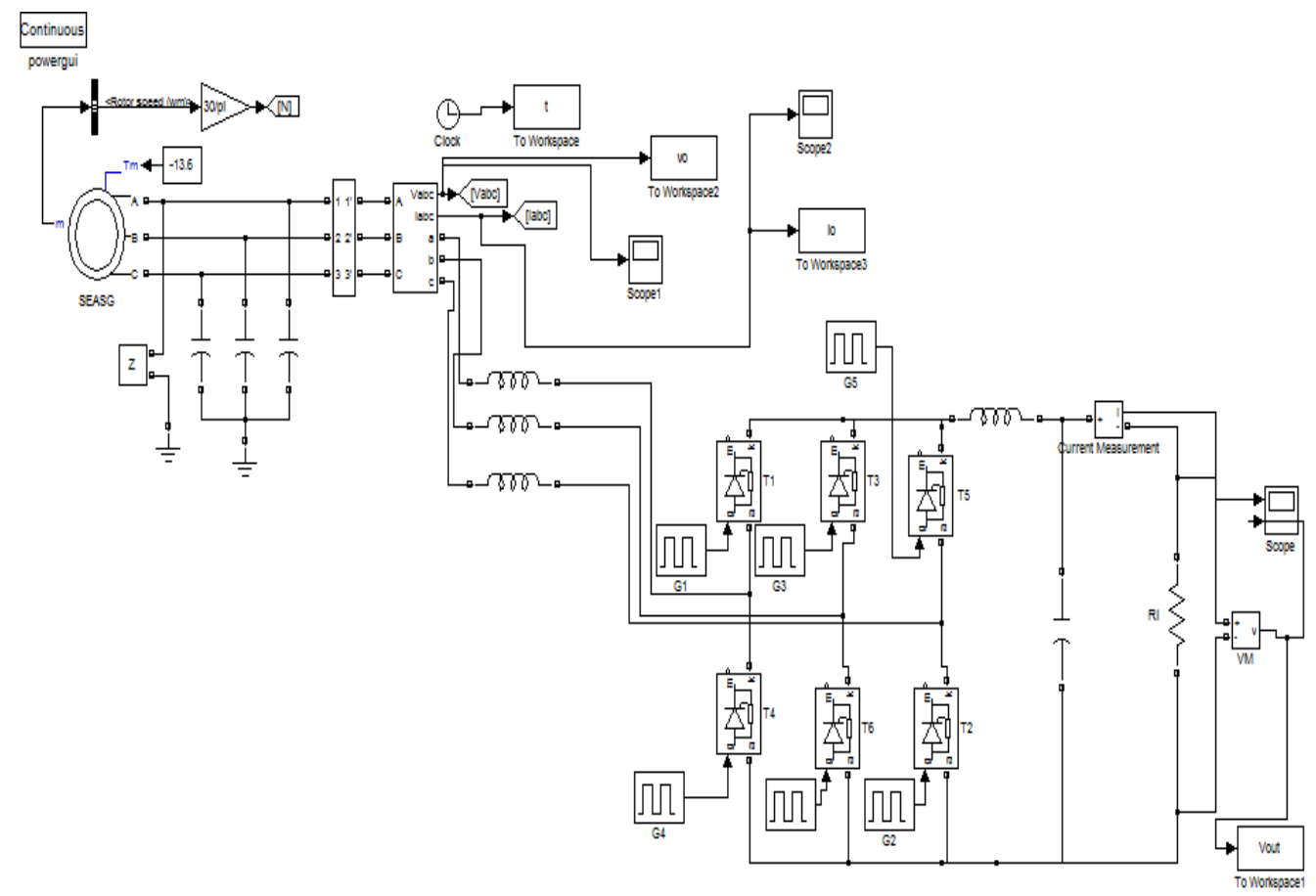

Fig:-1.8 SEIG with controlled rectifier load

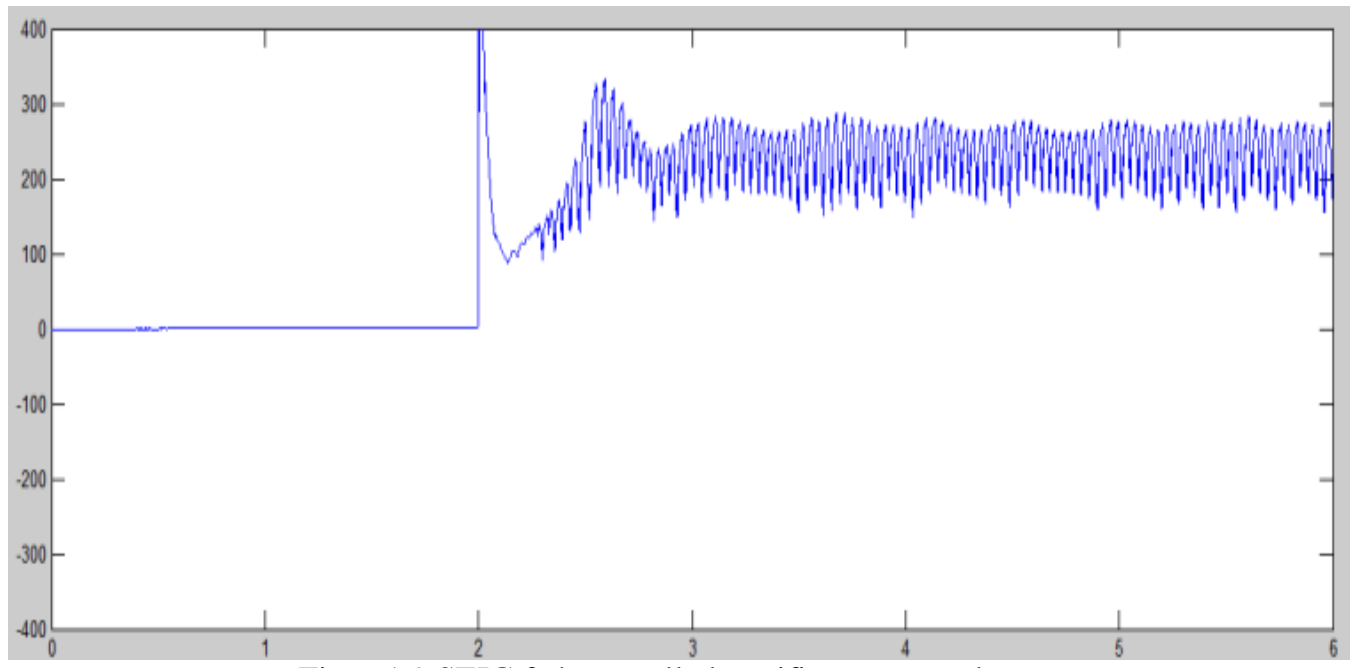

Fig: - 1.9 SEIG fed controlled rectifier output voltage.

\section{Harmonic analsys}

When the non linear (rectifier) load is connected to the terminals of a SEIG the undesired problems, due to harmonic currents, such as additional power losses, high-frequency pulsating torque, the output capacity etc. To evaluate the harmonic components that are present in the generated voltages, stator currents, and load currents under the steady state conditions is analysed. The quality of the generated output voltage is evaluated by the total harmonic distortion (THD). The THD is an index of the closeness in shape between the waveform and its fundamental component and is defined as

$$
T H D=\left[\left(\frac{v}{v_{1}}\right)^{2}-1\right]^{1 / 2}
$$

Where, V1 is the fundamental R.M.S component 


$$
H F=\left[\left(\frac{I}{I_{1}}\right)^{2}-1\right]^{1 / 2}
$$

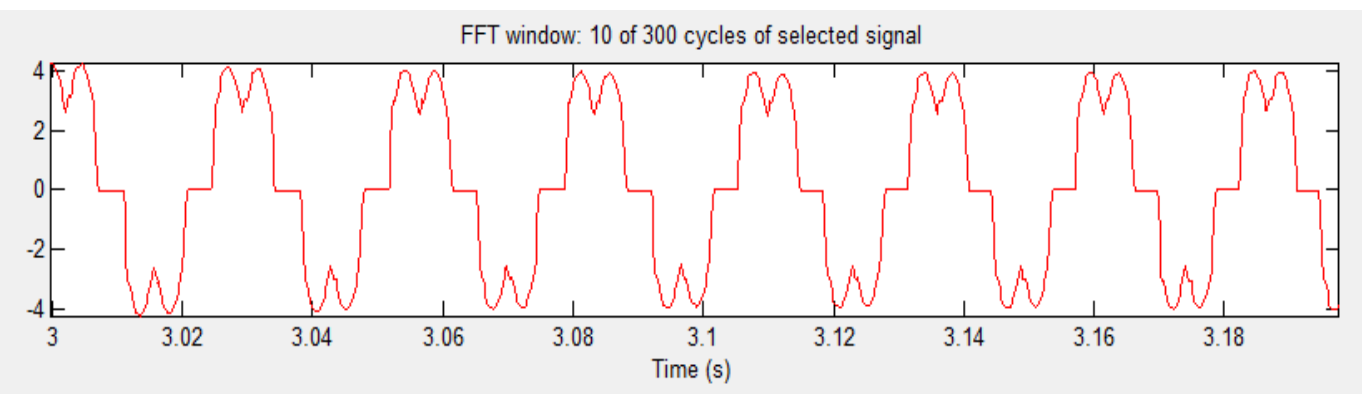

Fig:-1.10 SEIG line current due to diode rectifier hormonics

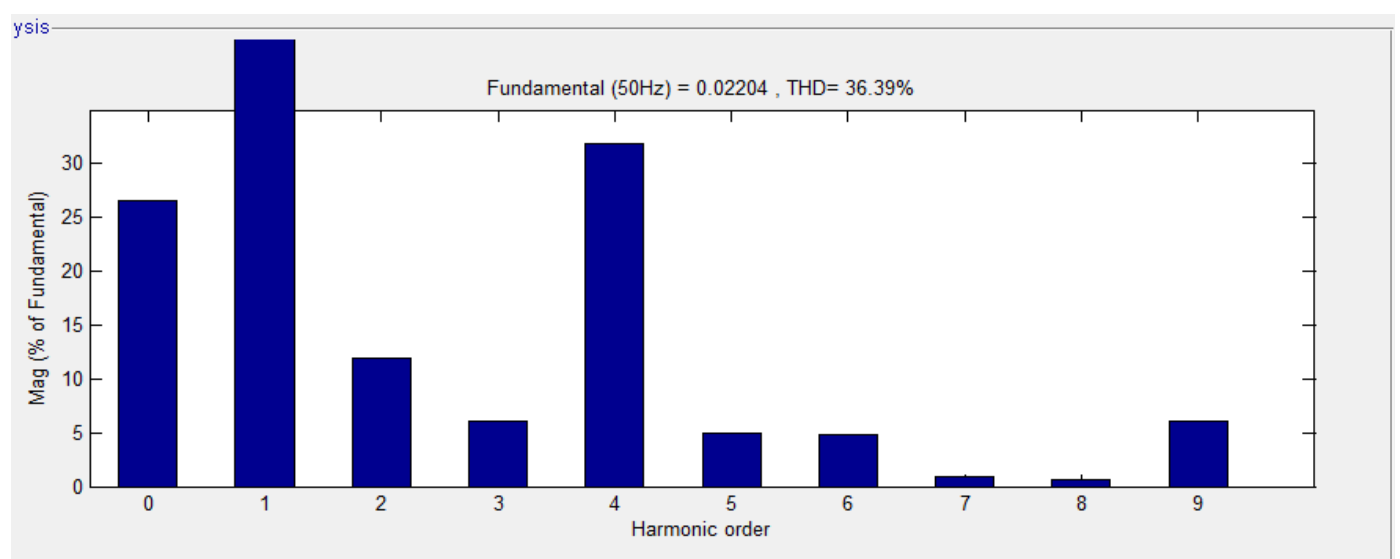

Fig:-1.11 SEIG line current harmonic order at 50hz.

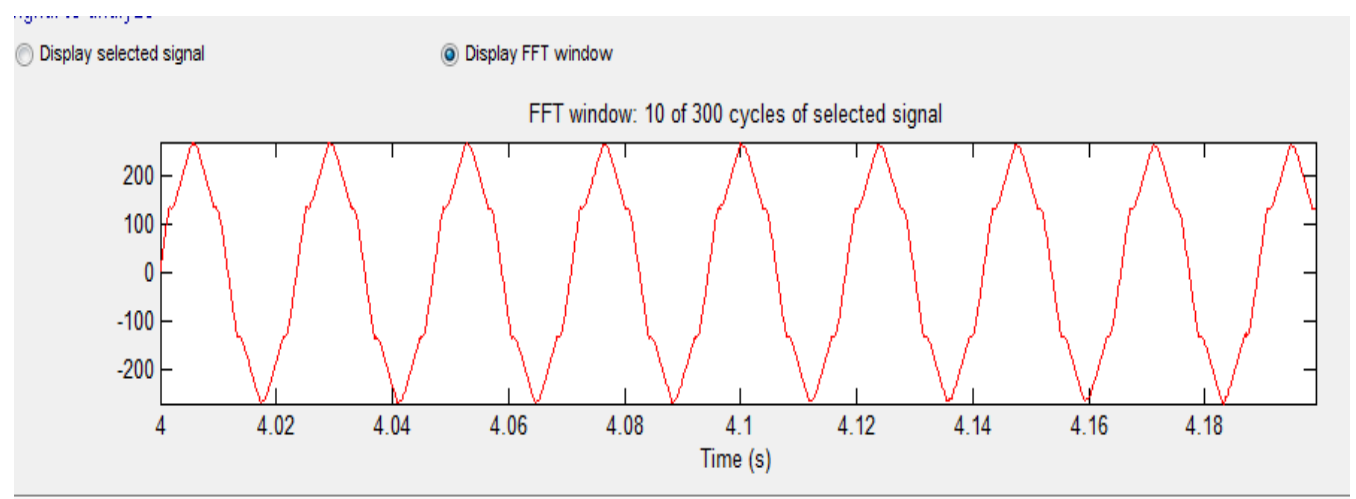

Fig:-1.12 SEIG phase voltage due to diode rectifier harmonics

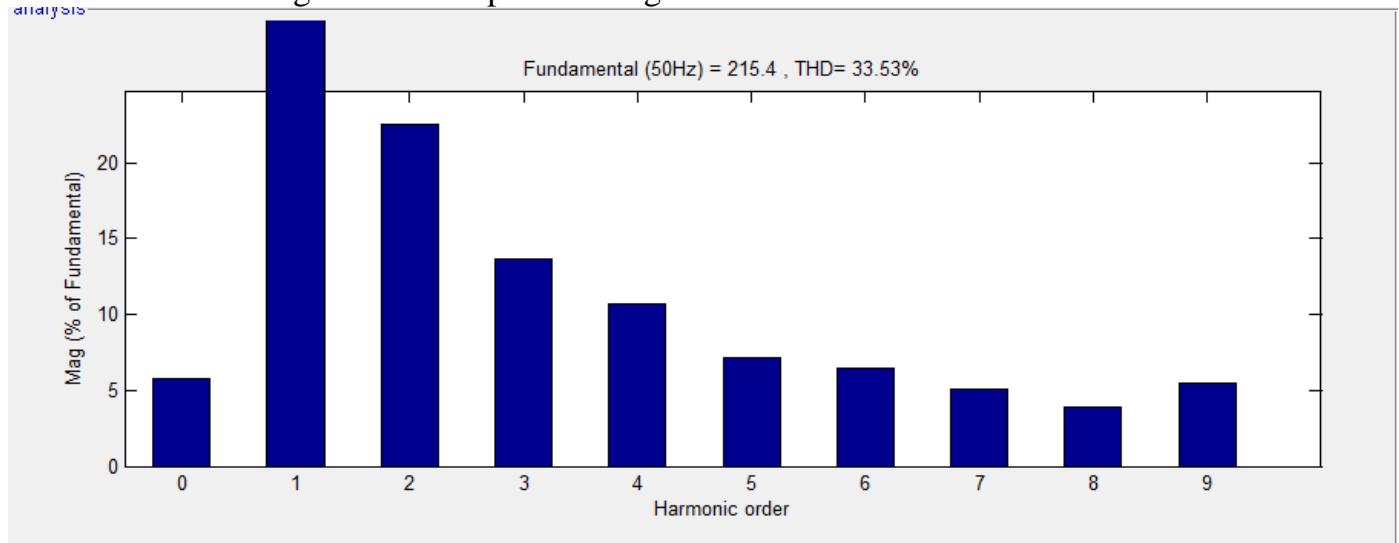

Fig:-1.13 SEIG phase voltage harmonic order at 50hz 


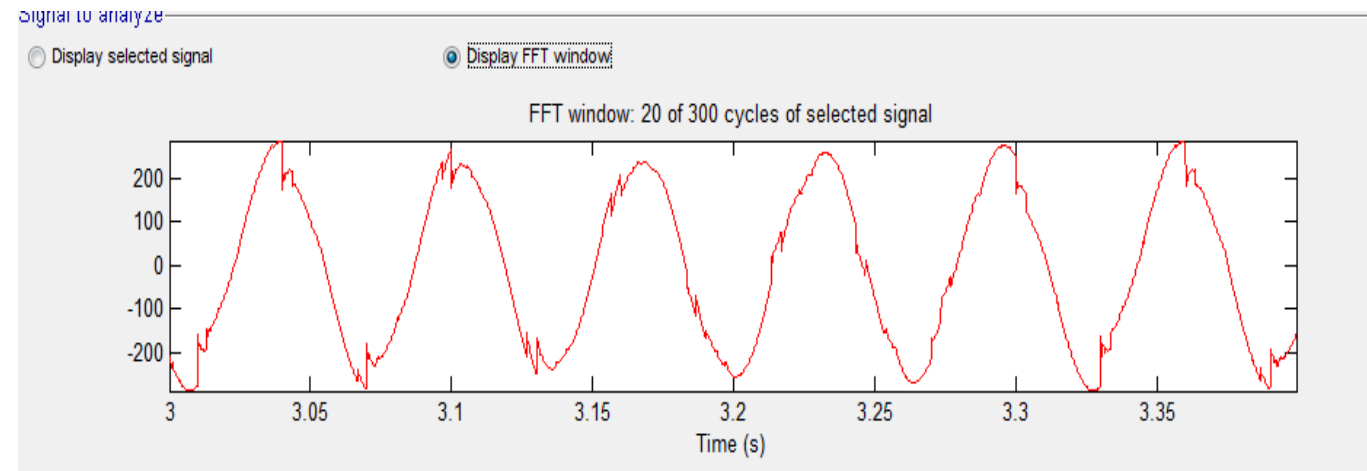

Fig:-1.14 SEIG phase voltege due controlled nonlinear( rectifier) load

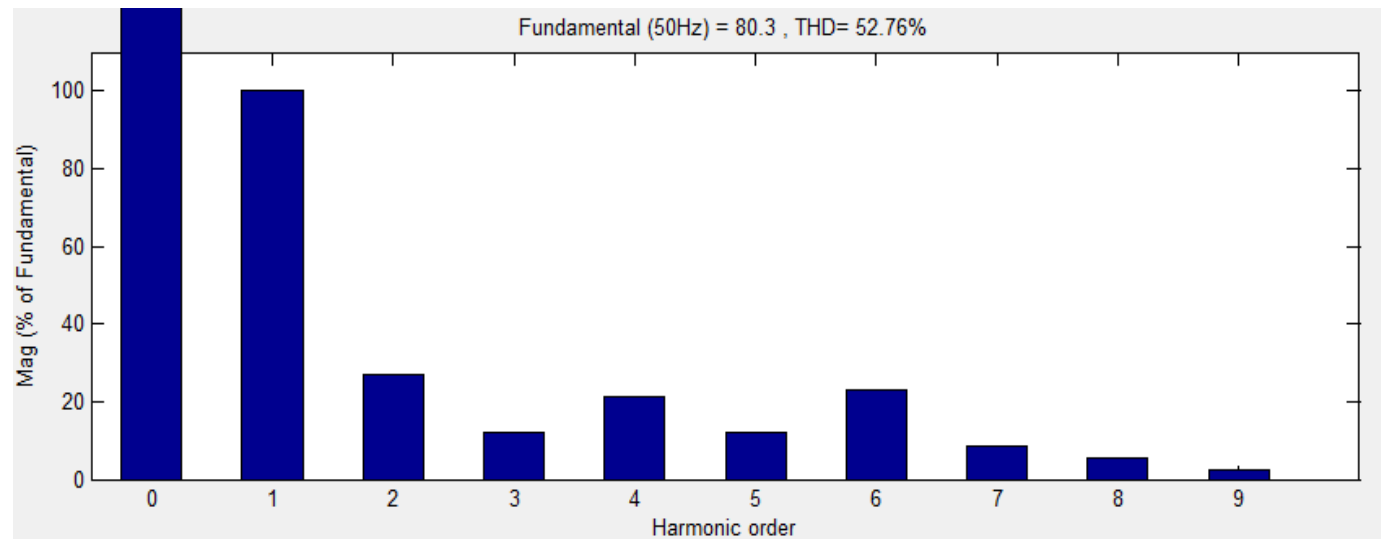

Fig:-1.15 SEIG phase voltage harmonic order at $50 \mathrm{hz}$

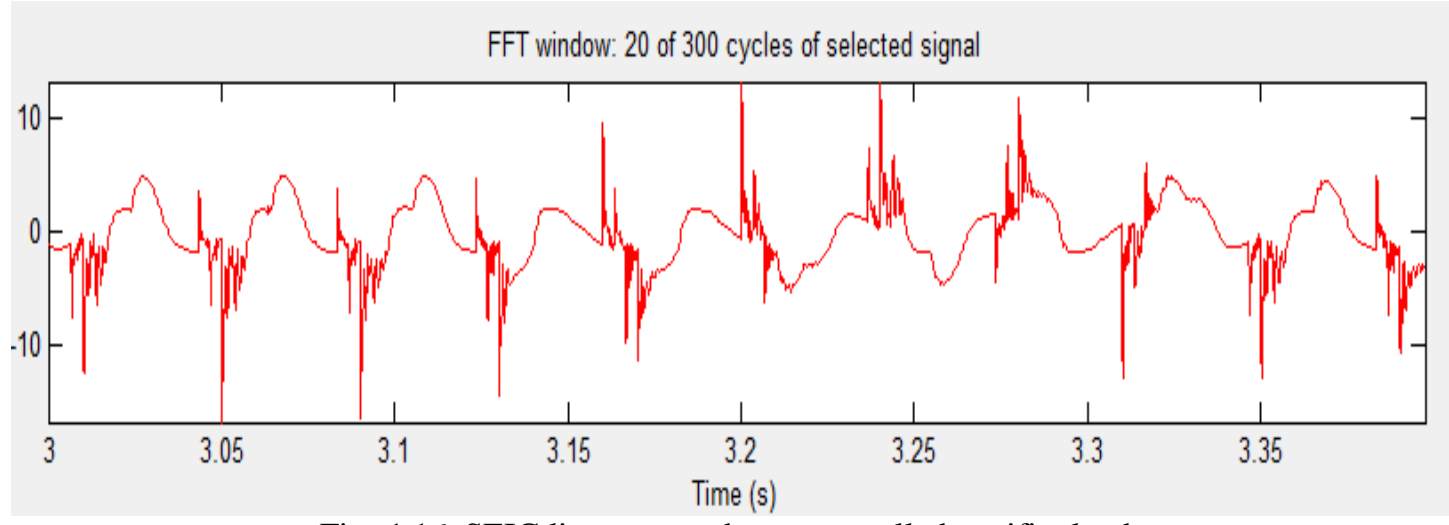

Fig:-1.16 .SEIG line current due to controlled rectifier load

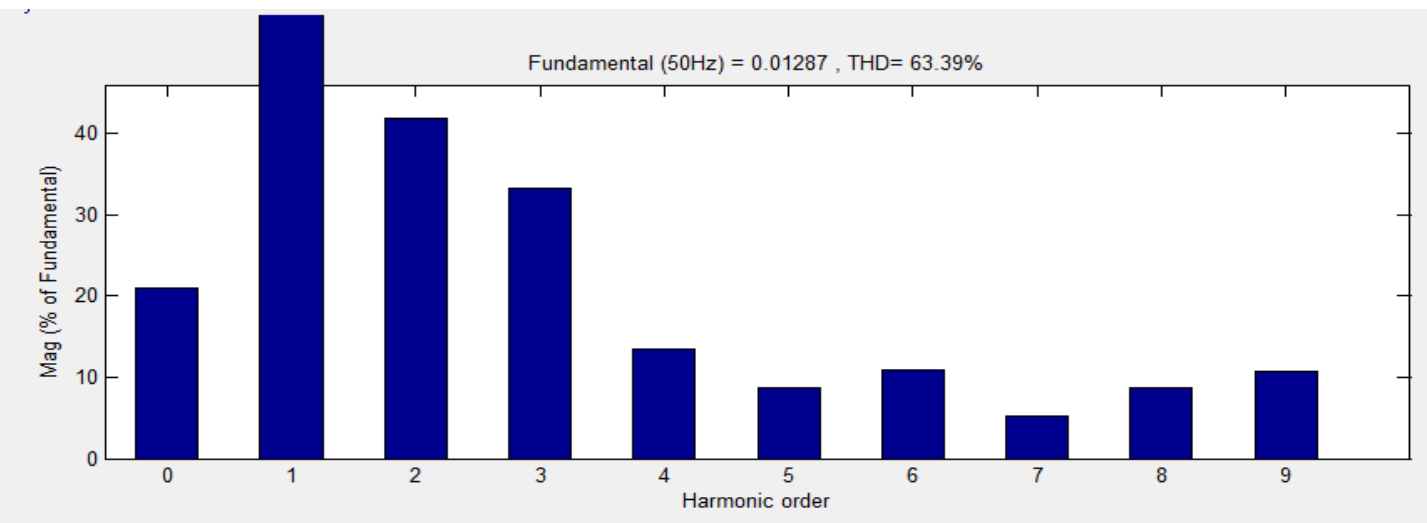

Fig:-1.17. SEIG line current harmonic order at 50hz.

At different loads the THD and HF are calculated. 


\section{Conclusions}

This paper has presented the performance of an isolated self-excited induction generator (SEIG) feeding a nonlinear (rectifier) load. The steady-state performances are investigated by using the hybrid induction machine model. The models of the multi-phase both un-controlled and controlled rectifiers are also formulated by using MATLAB/SIMULINK software. It has been shown that the developed models can work very well. Harmonic content caused by the nonlinear rectifier load are estimated with the FFT algorithm. Static DC loads as well as a dynamic DC motor load including the effect of the filter under steady-state conditions have been included. The harmonics of single stage and multi-phase rectifiers is analyzed.

\section{REFERENCES}

[1]. Basset E. D and Potter F. M., "Capacitive Excitation For Induction Generators,” AIEEE committee of Electrical Engineering, pp 535 $-545,1935$.

[2]. E. Barkle and R.W. Ferguson, "Induction Generator Theory and Application,” AIEE Trans., pt. III A, Vol.73, pp. 12-19, 1945.

[3]. R.C.Bansal,“Three-Phase Self-Excited Inducytion Generators: Over View,” IEEE Transaction On Enrgy Conversion, vol. 20, No.2, pp. $292-299,2005$

[4]. Saffet Ayasun and Chika O. Nwankpa, "Induction Motor Tests Using MATLAB/Simulink and Their Integration into Undergraduate Electric Machinery Courses" IEEE Transactions on Education, Vol. 48, No.1 Feb. 2005

[5]. Elder J. M., Boys J. T and Woodward J. L., “The Process Of Self Excitation In Induction Generators,” IEE Proc. Vol. 130, Pt. B. No. 2, pp $103-108,1983$.

[6]. Murthy, S.S., Singh B.P. et. al., "Studies Of The Conventional Induction Motor As Self-Excited Induction Generators," IEEE Transaction on energy conversion, Vol.3, No.4, pp $842-848,1988$.

[7]. S. Kulandhaivelu, K.K Ray, "Load control of a 3-ø self excited asynchronous generator," IJEST, Vol.3, pp.1103-1112 No.7, Feb. 2011.

[8]. S. Sharma, K.S . Sandhu, "Role of Reactive Power source on power quality of three phase self excited induction generator," WSEAS Trans on power system, Issue 4, Vol.3, Apr. 2008. 